\title{
PENGEMBANGAN MATERIAL RINGAN SERAT GELAS PADA INDUSTRI KERETA API
}

\author{
Oki Kurniawan \\ Akademi Perkeretaapian Indonesia \\ Jalan Tirta Raya I \\ Nambangan Lor, Mangunharjo \\ Sambirejo, Jiwan, Madiun 63129 \\ okik489@gmail.com
}

\author{
Willy Artha Wirawan \\ Akademi Perkeretaapian Indonesia \\ Jalan Tirta Raya I \\ Nambangan Lor, Mangunharjo \\ Sambirejo, Jiwan, Madiun 63129 \\ willy@pengajar.ppi.ac.id
}

\author{
Akbar Zulkarnain \\ Akademi Perkeretaapian Indonesia \\ Jalan Tirta Raya I \\ Nambangan Lor, Mangunharjo \\ Sambirejo, Jiwan, Madiun 63129 \\ akbar@ppi.ac.id
}

\begin{abstract}
The use of composite materials has been developed in the railroad transportation industry sector in Indonesia. For example, PT INKA has used composite materials with fiber glass reinforcement. The purpose of this study is to determine the characteristics of tensile strength and bending strength of the composite material so that it can be proposed to be further developed and utilized by the manufacturing industry, especially the railroad industry. In this study, 4 types of matrix variations were examined, namely epoxy, repoxy, polyester, and bhispenol using fiber glass reinforcement. Tensile strength and bending strength tests were performed in accordance with the ASTM D-638 and the ASTM D-790 standards, respectively. The results of this study indicate that the variation of the matrix is very influential on the tensile strength and bending strength of composite materials.
\end{abstract}

Keywords: composite material, glass fiber, tensile strength, bending strength

\begin{abstract}
Abstrak
Penggunaan material komposit mulai banyak dikembangkan di sektor industri trasportasi kereta api di Indonesia. Sebagai contoh, PT INKA sudah menggunakan material komposit dengan penguat serat gelas. Tujuan penelitian ini adalah untuk mengetahui karakteristik kekuatan tarik dan kekuatan bending material komposit agar dapat diusulkan untuk lebih dikembangkan dan dimanfaatkan oleh industri manufaktur, khususnya industri kereta api. Pada penelitian ini digunakan 4 jenis variasi matriks, yaitu epoxy, repoxy, polyester, dan bhispenol dengan menggunakan penguat serat gelas. Pengujian kekuatan tarik menggunakan standar ASTM D-638 dan pengujian bending menggunakan standar ASTM D-790. Hasil studi ini menunjukkan bahwa variasi matriks sangat berpengaruh pada kekuatan tarik maupun kekuatan bending material komposit.
\end{abstract}

Kata-kata kunci: material komposit, serat gelas, kekuatan tarik, kekuatan bending

\section{PENDAHULUAN}

Material komposit adalah material gabungan atau campuran dari dua atau lebih bahan pada skala makroskopis untuk membentuk material ketiga yang memiliki sifat baru yang lebih baik. Material komposit pada dasarnya terdiri atas pengikat (reinforcement) dan penguat (matriks). Material pengikat biasanya berupa bahan plastik atau polymer dan material penguat umumnya adalah serat yang terbuat dari bahan yang kuat dengan masing-masing memiliki sifat yang berbeda. Perbedaan ini akan berpengaruh terhadap komposit yang telah dibuat. Material penguat atau matriks merupakan penyusun dengan fraksi volume terbesar. Matriks yang sering digunakan dalam penelitian adalah matriks polymer, yang memiliki beberapa jenis, seperti epoxy, polyester, bhispenol, dan repoxy. 
Material komposit yang sudah mulai banyak digunakan dalam dunia industri adalah material komposit dengan penguat berupa serat gelas atau fiber glass. Jenis serat ini memiliki kekuatan dan kekakuan spesifik yang jauh lebih tinggi dibandingkan kekuatan dan kekakuan bahan lainnya, sehingga dapat didesain sesuai dengan kebutuhan. (Ichsan dan Irfa'i, 2015).

Serat gelas atau fiber glass saat ini sudah sering digunakan sebagai penguat oleh industri manufaktur kereta api, khususnya PT INKA. Serat gelas ini memiliki sifat yang kuat, ringan, dan lebih memiliki nilai ekonomis jika dibandingkan dengan serat sistetis lainnya. Serat gelas mampu mencapai kekuatan tarik 201,5 MPa, sehingga sangat berpotensi sebagai penguat atau reinforcement (Kuntari dan Surasno, 2009).

Saat ini PT INKA, sebagai satu-satunya industri manufaktur kereta api di Indonesia, sudah banyak menggunakan material komposit sebagai komponen kereta, seperti interior, panel, dan dinding (lihat Gambar 1). Namun, PT INKA hanya mengunakan satu jenis matriks saja, yaitu polyester. Pada penelitian ini digunakan 4 jenis matriks, yaitu epoxy, repoxy, polyester, dan bhispenol sebagai bahan pengikat utama.

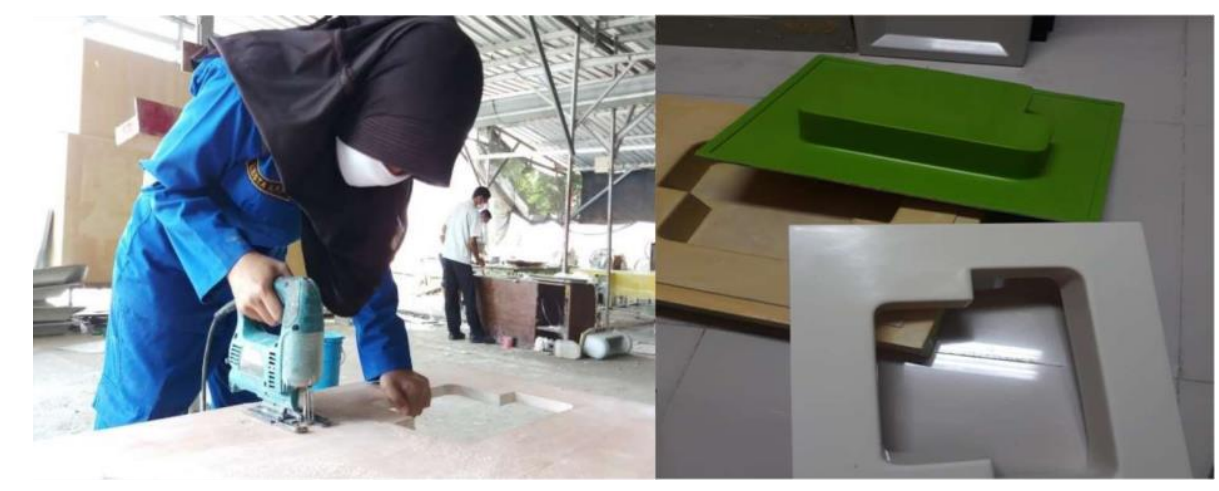

Gambar 1 Produk Komposit PT INKA

Kekuatan mekanik dan sifat mekanik suatu material dapat dilihat melalui proses pengujian, seperti pengujian tarik dan pengujian bending. Pada penelitian ini dianalisis sifat mekanik suatu material melalui proses pengujian tarik, dengan standar ASTM D-638, dan pengujian bending, dengan standar ASTM D-790, untuk melihat kekuatan tarik dan kekuatan bending material tersebut. Tujuan penelitian ini adalah untuk mengetahui pengaruh variasi jenis matrik, sehingga dapat ditemukan komposisi komposit antara penguat dan pengikat yang terbaik.

Penelitian ini menggunakan metode eksperimental untuk mendapatkan data kekuatan tarik dan kekuatan bending maksimal material komposit. Material komposit yang dikaji terdiri atas serat gelas, sebagai unsur pengikat, dan variasi 4 matriks polimer, yaitu epoxy, repoxy, polyester, dan bhispenol, sebagai unsur penguatnya. Spesimen untuk pengujian dapat dilihat pada Gambar 2.

Susunan laminasi serat gelas terdiri atas 4 lapisan, yaitu 2 lapisan serat 300 gram/meter ${ }^{2}$ dan 2 lapisan serat 450 gram $/$ meter $^{2}$, dengan perbandingan komposisi matriks atau penguat dengan serat 60:40 dan ditambah dengan larutan hardener untuk epoxy, katalis mexpo untuk repoxy, polyester, dan bhispenol. Setelah itu, spesimen untuk pengujian yang sudah jadi didiamkan pada suhu ruangan selama 7 hari. 


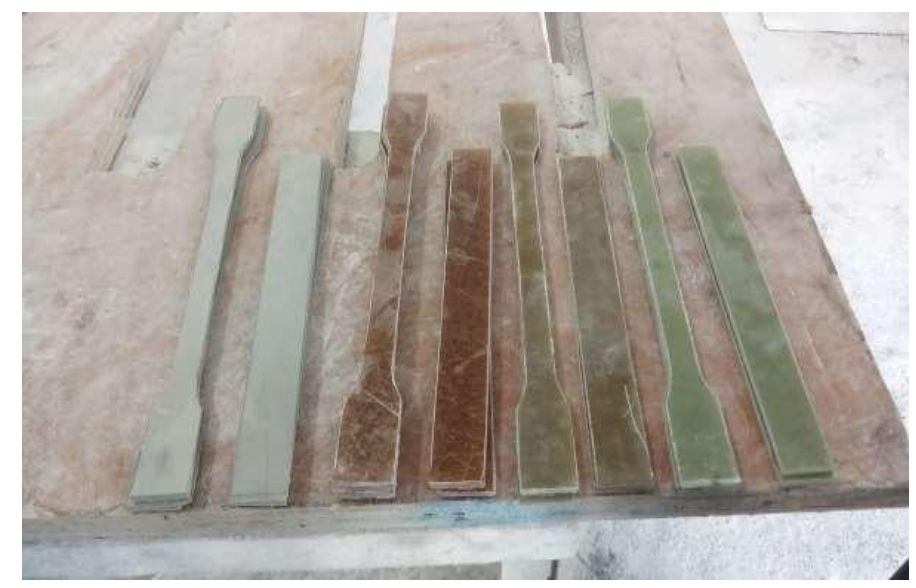

Gambar 2 Spesimen Uji Tarik dan Bending

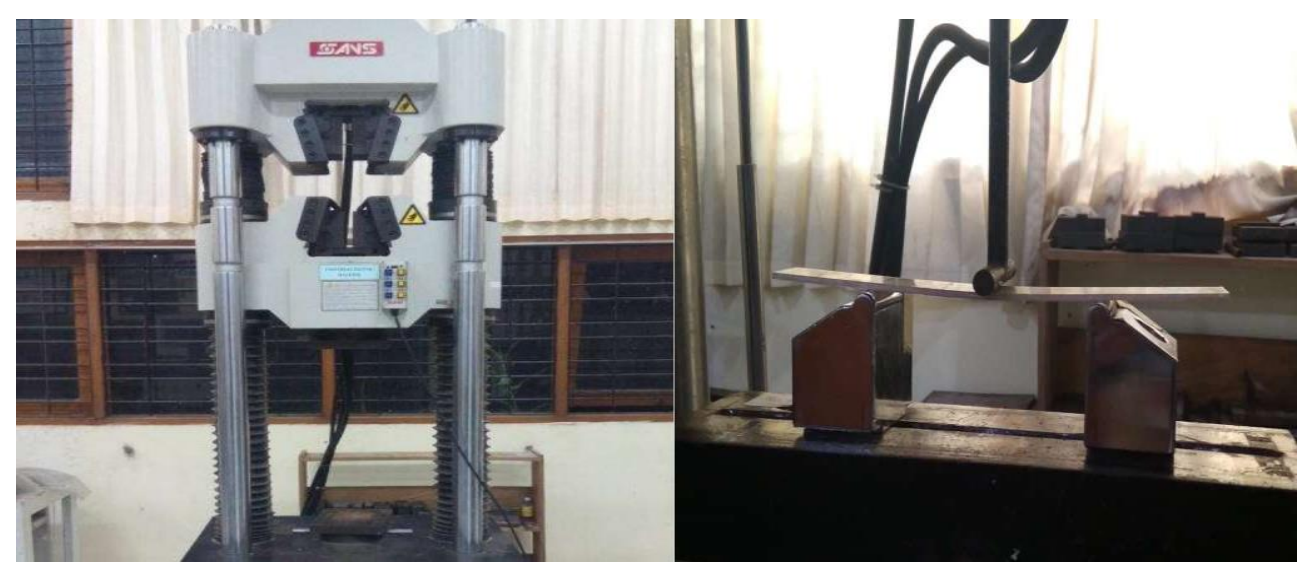

Gambar 3 Pengujian Tarik dan Bending

Proses pembuatan komposit pada penelitian ini menggunakan Metode Vacuum Bagging, yang merupakan penggembangan Metode Hand Lay Up, tetapi lebih kompleks karena udara atau void yang ada dalam laminasi akan divakum sehingga dapat meningkatkan percampuran bahan-bahan. Proses pengujian spesimen komposit tarik dilakukan dengan menarik spesimen sampai patah, sedangkan uji bending dilakukan dengan Metode Three Point Bending, yang menggunakan batang sederhana dengan 2 titik dudukan pembebanan di tengah batang uji, menggunakan Universal Testing Machine (UTM). Proses pengujian tarik dan pengujian bending dapat dilihat pada Gambar 3.

\section{HASIL DAN PEMBAHASAN}

\section{Pengujian Tarik}

Sebagai pembanding pada studi ini, digunakan spesimen dari PT INKA, yang mempunyai kekuatan tarik maksimal sebesar 87,33 MPa dan regangan maksimal 0,01688\%. Hubungan tegangan dan regangan spesimen dari PT INKA ditunjukkan pada Gambar 4. 


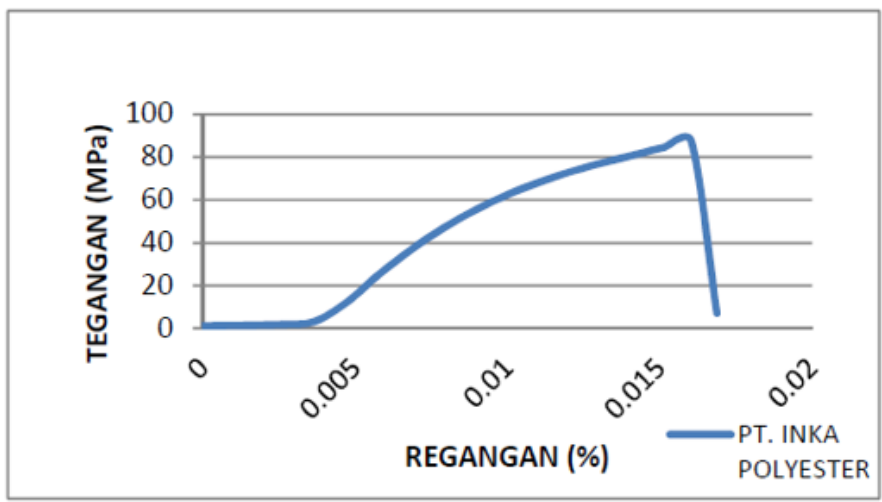

Gambar 4 Hubungan Tegangan dan Regangan Spesimen Uji PT INKA

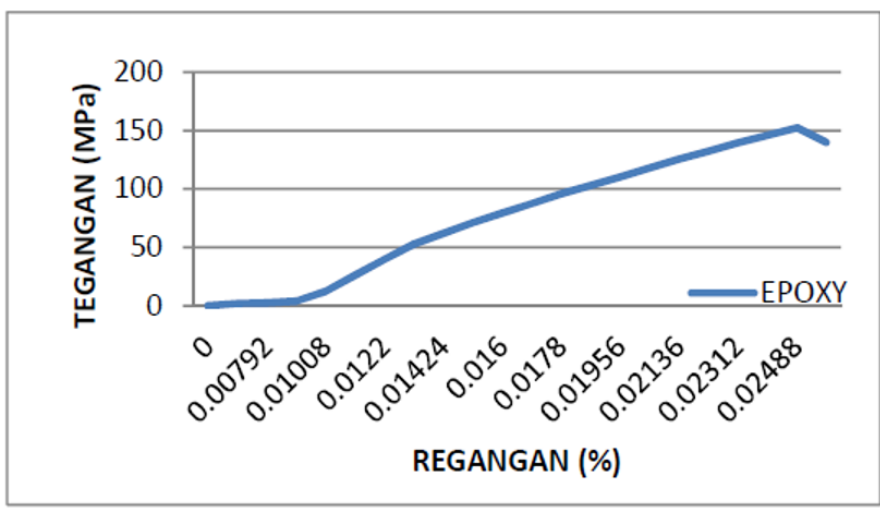

Gambar 5 Hubungan Tegangan dan Regangan Matriks Epoxy

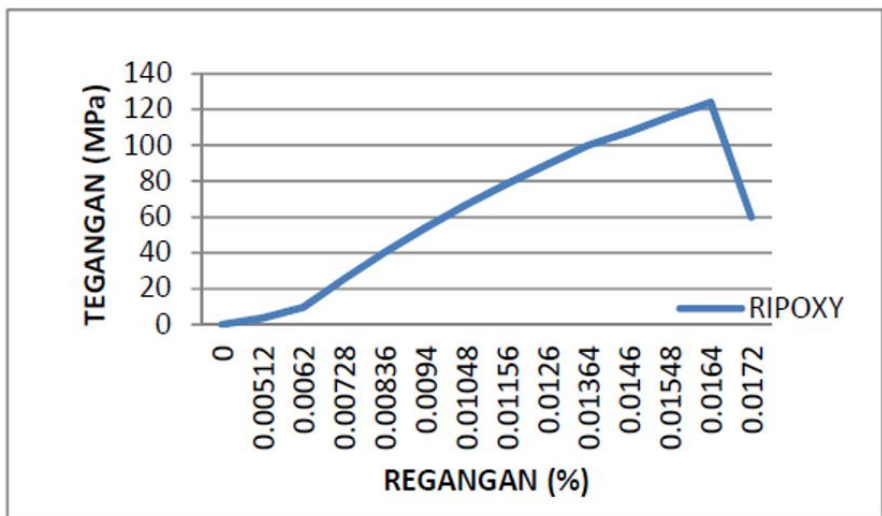

Gambar 6 Hubungan Tegangan dan Regangan Matriks Repoxy

Spesimen untuk uji kekuatan tarik pada penelitian ini memiliki nilai kekuatan tarik maksimum yang bervariasi, bergantung pada matriksnya. Spesimen dengan matrik epoxy memiliki nilai kekuatan tarik maksimum sebesar 152,5 MPa dan nilai regangan maksimal $0,0258 \%$, seperti terlihat pada Gambar 5. Sedangkan spesimen dengan matriks repoxy memiliki kekuatan tarik maksimum $124 \mathrm{MPa}$ dan regangan maksimum 0,0172\%, seperti yang ada pada Gambar 6. Sementara itu, spesimen yang menggunakan matriks bhispenol 
memiliki kekuatan tarik maksimum 168,5 MPa dan regangan maksimum 0,01952\%, yang ditunjukkan pada Gambar 7, dan spesimen dengan matriks polyester memiliki kuat tarik maksimum 198,5 MPa dan regangan maksimum 0,02251\% (lihat Gambar 8). Hasil ini menunjukkan bahwa spesimen yang menggunakan matriks polyester mempunyai kuat tarik maksimum terbesar di antara spesimen-spesimen yang diuji lainnya (lihat Gambar 9).

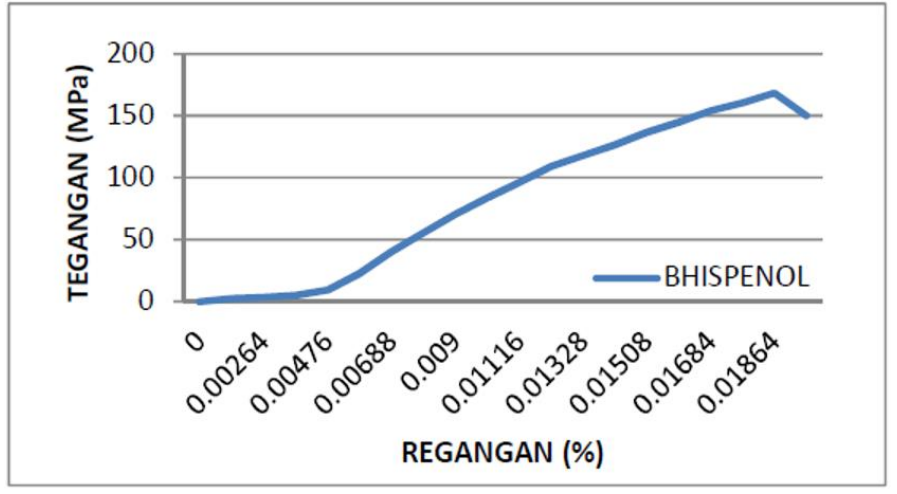

Gambar 7 Hubungan Tegangan dan Regangan Matriks Bisphenol

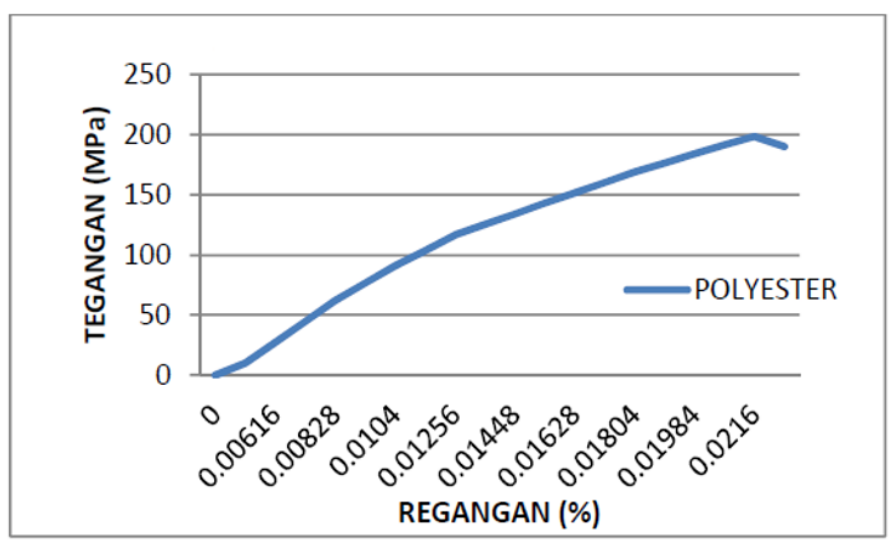

Gambar 8 Hubungan Tegangan dan Regangan Matriks Polyester

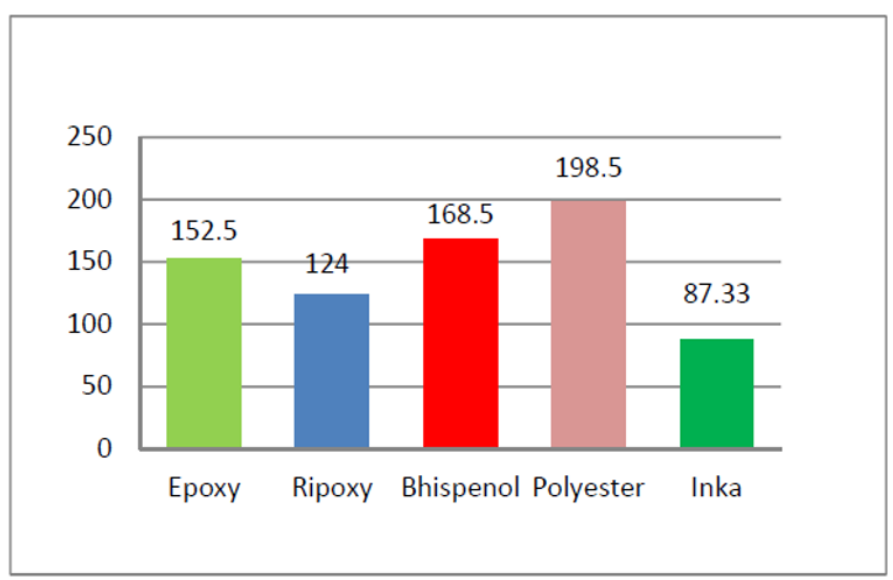

Gambar 9 Perbandingan Kekuatan Tarik Maksimum 
Perbedaan karakteristik tiap-tiap matriks juga dapat dilihat ada jenis atau bentuk patahan yang diberikan oleh pengujian tarik. Gambar 10 menunjukkan hasil patahan pengujian tarik masing-masing material komposit dengan variasi 4 matriks.

Dari berbagai macam bentuk patahan spesimen uji tarik terlihat bahwa resin polyester mengalami jenis patahan multipel area. Hal ini sesuai dengan penelitian yang dilakukan oleh Diharjo (2006), yang menyatakan bahwa komposit dengan bentuk patahan multipel area pada umumnya memiliki kekuatan yang sangat tinggi. Resin bhispenol juga mengalami bentuk patahan multipel area dan hal ini juga didukung oleh hasil uji yang tinggi. Sedangkan resin repoxy, yang memiliki bentuk patahan tunggal, dan resin epoxy, yang memiliki bentuk patahan pull out, memiliki kekuatan yang lebih rendah.

Penelitian ini juga memberikan hasil yang lebih baik daripada hasil yang diberikan oleh spesimen PT INKA. Hal ini dapat terjadi karena proses atau metode yang digunakan pada PT INKA berbeda dengan proses yang digunakan pada studi ini serta perbedaan karakteristik pada matriks yang mengikat serat. Matriks polyester memiliki nilai kekuatan tarik tertinggi karena matriks ini memiliki nilai viskositas yang rendah, sehingga resin dapat meresap dan mengisi seluruh ruang yang ada di serat.

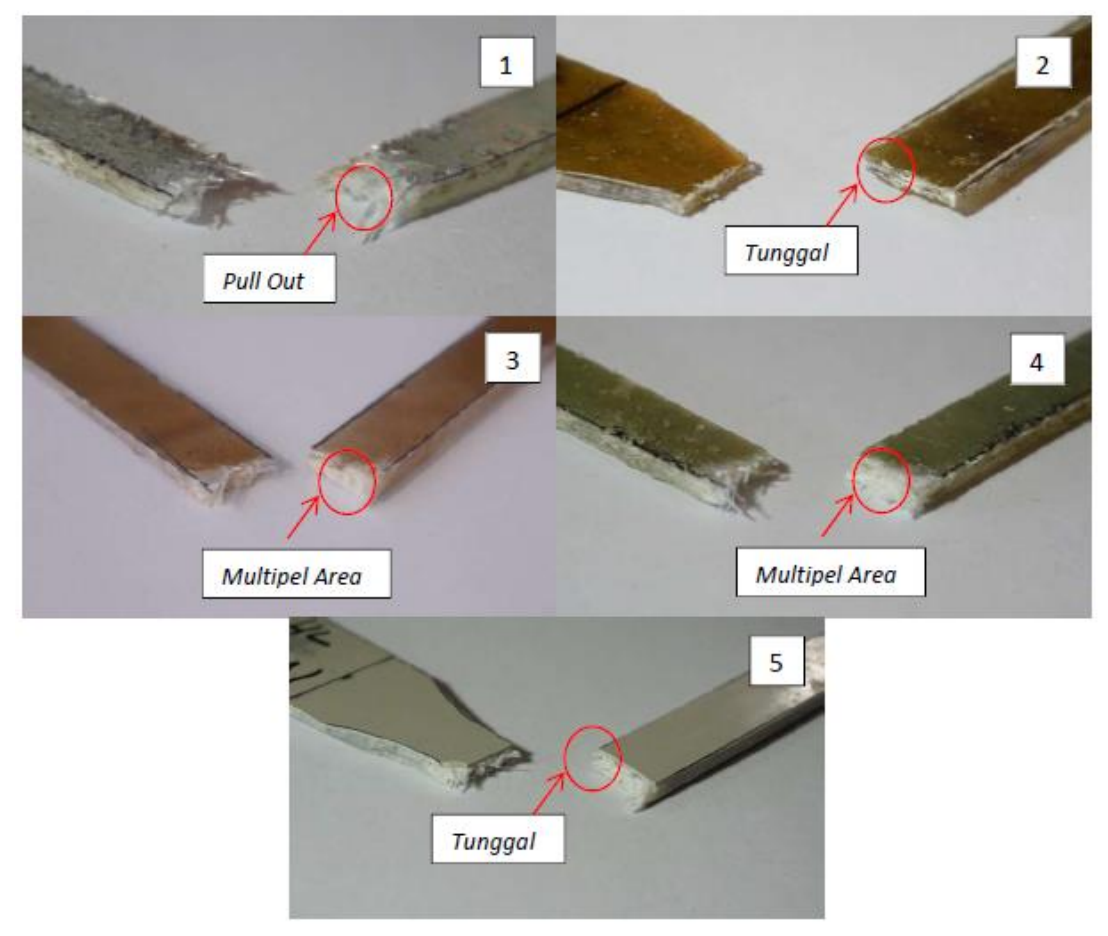

Gambar 10 Bentuk Patahan Uji Tarik: (1) Resin Epoxy (2) Resin Repoxy (3) Resin Bisphenol (4) Resin Polyester (5) Spesimen PT INKA

Perbedaan metode pembuatan spesimen juga dapat menjadi salah satu penyebab perbedaan hasil uji. Saat ini PT INKA menggunakan metode hand lay up. Pada metode ini, udara atau void masih dapat terperangkap di dalam laminasi, yang selanjutnya dapat berpengaruh pada hasil uji. Sedangkan pada penelitian ini digunakan metode vacuum bagging, sehingga udara yang terperangkap dapat keluar dari laminasi melalui proses vakum. 


\section{Pengujian Bending}

Pada studi ini, pengujian bending dilakukan dengan menggunakan metode three point bending. Spesimen dari PT INKA mempunyai kekuatan bending 616,61 MPa. Sedangkan kekuatan bending spesimen pada penelitian ini, dimulai dengan yang paling rendah, adalah 470,73 MPa untuk spesimen dengan matriks epoxy, 596,88 MPa untuk spesimen dengan matriks repoxy, 1030,35 MPa untuk spesimen dengan matriks bhispenol, dan 1387,38 MPa untuk spesimen dengan matriks polyester. Perbandingan hasil pengujian kekuatan bending ini dapat dilihat pada Gambar 11.

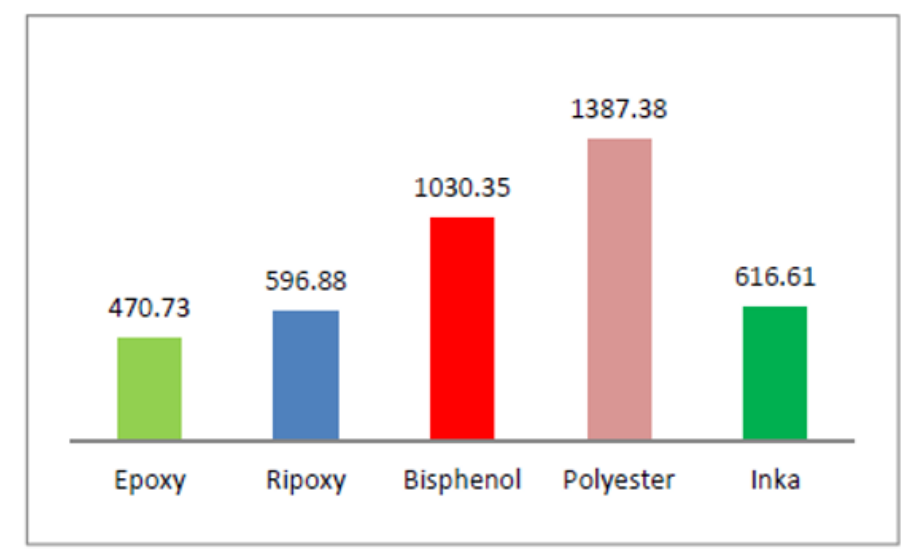

Gambar 11 Perbandingan Kekuatan Bending

Karakteristik material komposit juga dapat dilihat berdasarkan bentuk patahan spesimen untuk pengujian bending. Bentuk patahan pada uji bending ini dapat dilihat pada Gambar 12. Bentuk patahan uji bending tersebut menunjukkan bahwa spesimen yang diuji memiliki kekuatan bending yang cukup tinggi dan memenuhi standar yang digunakan oleh PT INKA, yaitu minimum $140 \mathrm{MPa}$. Penggunaan resin yang baik dapat diketahui dan dilihat dari patahan yang dihasilkan dari uji bending. Hasil patahan pada studi ini menunjukkan bahwa resin epoxy memiliki karakteristik ulet, karena resin epoxy mempunyai viskositas yang rendah, sehingga resin ini sangat mudah untuk divakum.

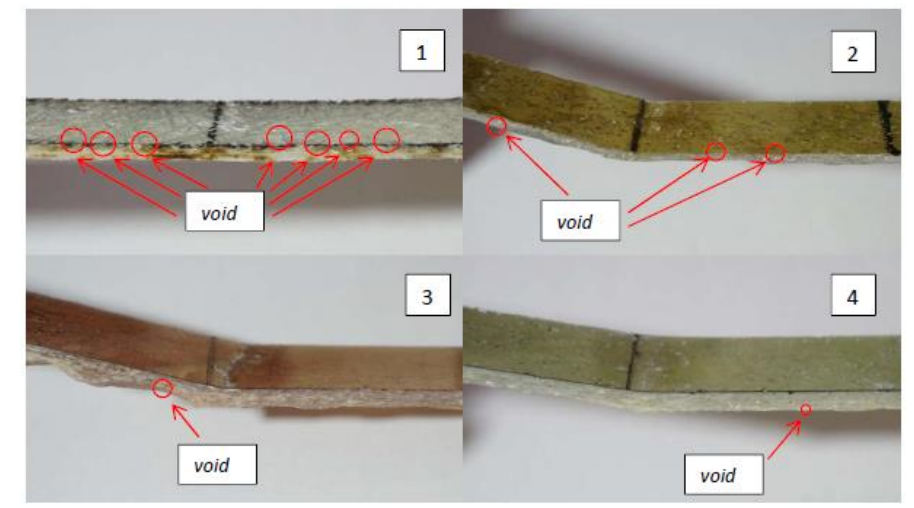

Gambar 12 Bentuk Patahan Uji Bending: (1) Resin Epoxy (2) Resin Repoxy

(3) Resin Bisphenol (4) Resin Polyester 


\section{KESIMPULAN}

Hasil penelitian ini menunjukkan bahwa keempat jenis matriks yang diamati memberikan hasil kekuatan tarik dan bending yang berbeda-beda, bergantung pada karakteristik masing-masing matriks. Matriks polyester menghasilkan kekuatan tarik maksimum sebesar 198,5 MPa dengan kekuatan bending 1387,38 MPa, matriks bhispenol mencapai nilai kekuatan tarik maksimum 168,5 MPa dengan kekuatan bending 1.030,35 MPa, matriks epoxy memiliki kekuatan tarik maksimum 152,5 MPa dengan kekuatan bending 470,73 $\mathrm{MPa}$, serta matriks repoxy mempunyai kekuatan tarik maksimum $124 \mathrm{MPa}$ dengan kekuatan bending 596,88 MPa.

Hasil penelitian ini memenuhi standar yang digunakan oleh PT INKA. Dengan demikian hasil penelitian ini dapat direkomendasikan ke perusahaan manufaktur untuk selanjutnya dapat dipertimbangkan dan dikembangkan sesuai dengan kebutuhan perusahaan.

\section{DAFTAR PUSTAKA}

American Standard Testing and Material. Standard Test Method for Flexural Properties of Unreinforced and Reinforced Plastic and Electrical Insulating Material, D790. West Conshohocken, PA.

American Standard Testing and Material. Standard Test Method for Tensile Properties of Plastic, D638. West Conshohocken, PA.

Diharjo, K. 2006. Pengaruh Perlakuan Alkali terhadap Sifat Tarik Bahan Komposit Serat Rami-Polyester. Jurnal Teknik Mesin, 8 (1): 8-13.

Ichsan, R.N. dan Irfa'i, M.A. 2015. Pengaruh Susunan Lamina Komposit Berpenguat Serat E-Glass dan Serat Carbon terhadap Kekuatan Tarik dengan Matriks Polyester. Jurnal Teknik Mesin, 3 (3): 32-39.

Kuntari dan Surasno. 2009. Komposit Resin Epoxy dan Serat Gelas untuk Komponen Kereta Api. Bandung: Balai Besar Bahan dan Barang Teknik. 